\title{
Annotations
}

\section{Pharmacological manipulation of the ductus arteriosus}

\section{Physiological considerations}

The postnatal rise in blood oxygen tension is widely recognised as the trigger to closure of the ductus arteriosus. The prostaglandins are increasingly recognised as the mediators of this phenomenon. ${ }^{1}$ One suggested mechanism is that increased oxygen tension may promote the conversion of arachidonic acid to prostaglandin $F_{2 \alpha}$, which is known to be present in ductus arteriosus tissue and is a ductus constrictor. Another is that patency of the fetal ductus arteriosus may be actively sustained by intramural prostaglandin $\mathrm{E}_{2}\left(\mathrm{PGE}_{2}\right)$ and that postnatal exposure to oxygen reduces the responsiveness of the ductus to $\mathrm{PGE}_{2}$. There are certain clinical conditions in which the oxygen trigger does not seem to operate fully-for example, the ductus arteriosus often closes in congenital right heart obstructive lesions despite severe hypoxaemia, while it often remains patent in premature infants despite normal blood oxygen tensions. Treatment has been directed on the one hand towards the use of the $\mathrm{E}$ type prostaglandins to maintain ductus arteriosus patency and on the other towards the drug inhibition of prostaglandin synthesis to encourage ductus constriction. Indomethacin has been the drug most widely used as a prostaglandin synthetase inhibitor.

\section{Management of patent ductus arteriosus in the premature infant}

The demonstration that administration of indomethacin could achieve closure of patent ductus arteriosus in premature infants led to a major collaborative randomised trial in the United States. ${ }^{2}$ Approximately $20 \%$ of 3559 infants weighing $1750 \mathrm{~g}$ or less met the criteria of having a 'haemodynamically significant' patent ductus arteriosus, including the need for ventilatory support. Infants were excluded if there was poor renal function, a bleeding tendency, or necrotising enterocolitis. Approximately $10 \%$ of the whole group of infants consequently entered the trial.

All infants were given conventional medical treatment, including fluid restriction and diuretics.
Indomethacin was either given at the beginning of 'usual medical therapy' or after $36-48$ hours of treatment with placebo or not at all, the groups having been randomised and the physicians 'blinded'. Surgical ligation of the patent ductus arteriosus was undertaken if medical treatment failed in any of the groups.

At 48 hours after treatment $79 \%$ of infants who had received indomethacin no longer had a 'haemodynamically significant' patent ductus arteriosus compared with $28 \%$ of those who had received placebo. The ductus arteriosus reopened in $26 \%$ of those who received indomethacin but it subsequently closed again in most of them. Overall, permanent closure of the ductus arteriosus occurred without the need for surgery in $79 \%$ of the infants who received indomethacin and in $35 \%$ of those who received placebo. In infants whose birth weight was less than $1000 \mathrm{~g}$ the closure rate associated with treatment with indomethacin was three times the spontaneous closure rate but the incidence of indomethacin failures was also slightly higher than in infants weighing more than $1000 \mathrm{~g}$.

The overall mortality did not differ significantly whether infants were given usual medical treatment with indomethacin initially or later or whether they proceeded to surgical ligation of the ductus arteriosus having been in the placebo or the indomethacin group. The surgical group, however, had a higher complication rate, especially pneumothorax and retrolental fibroplasia, and the infants who were given indomethacin as part of the initial treatment had a higher incidence of bleeding than those to whom it was given only when usual medical treatment had failed. Bronchopulmonary dysplasia and necrotising enterocolitis had a similar incidence in each of these groups. In a follow up evaluation at the age of 1 year there were no significant differences between the groups in terms of the proportion of infants with poor outcome. ${ }^{3}$

Conclusions. There seems to be some merit in using intravenous indomethacin in those infants with a notable patent ductus arteriosus who do not respond to 36-48 hours of fluid restriction and diuretics and in whom there is no contraindication to its use. 
Approximately one quarter of all infants with a haemodynamically significant patent ductus arteriosus would then probably require surgical closure compared with two thirds if indomethacin was not used. The multi-centre study did not report whether the results varied from one centre to another. The timing of surgical closure of the ductus would probably have been based on the individual clinical assessment of each infant and might conceivably have influenced the outcome in the various centres. Small randomised studies have been reported in which infants were given indomethacin as a prophylactic measure. ${ }^{4}$ Although a lower incidence of subsequent appreciable shunting was shown, there were more complications, and the overall benefits of this strategy must remain speculative.

Principles of management. A firm policy will often depend on the experience of the individual centre and the local surgical results. When optimal conditions prevail for both medical and surgical management it seems reasonable to use indomethacin after 36-48 hours of fluid restriction, diuretics, and other routine measures. The recommended initial intravenous dose is $0.2 \mathrm{mg} / \mathrm{kg}$ body weight, repeated at 12 hourly intervals for a total of three doses. The second or third dose should not be given if contraindications develop or if there is evidence that complete closure of the ductus arteriosus has already occurred. In those infants who are 8 days or older the second and third doses of indomethacin may be increased to $0.25 \mathrm{mg} / \mathrm{kg}$ body weight because there is evidence that indomethacin is metabolised more rapidly by the premature infant as postnatal age advances. If the patent ductus arteriosus remains significant early surgical ligation should be undertaken. If indomethacin induces 'closure' and the ductus then 'reopens' a further three doses of indomethacin may be tried before resorting to ligation. The good surgical results in the major cardiac surgical centres justify fairly early referral for ligation.

\section{Ductus dependent congenital heart disease}

The E type prostaglandins: pathophysiological considerations. In early clinical studies infusions of either prostaglandins $\mathrm{E}_{1}$ or $\mathrm{E}_{2}\left(\mathrm{PGE}_{1}\right.$ or $\left.\mathrm{PGE}_{2}\right)$ were consistently effective in improving the oxygenation of neonates whose pulmonary blood flow depended on patency of the ductus arteriosus. ${ }^{5-7}$ Infusions of $\mathrm{PGE}_{1}$ also proved helpful in neonates with interrupted aortic arch, juxtaductal coarctation of the aorta and hypoplastic left heart syndrome, ${ }^{8}$ and, more recently, critical aortic stenosis; ductus patency allowed the descending aorta and kidneys to be perfused from the pulmonary artery. The other application of treatment with prostaglandin $E$ is the presence of complete transposition of the great arteries when interatrial mixing is poor, either before or after balloon atrial septostomy. ${ }^{7}$ The increased flow through the ductus arteriosus from the aorta to the pulmonary artery then results in an increase in pulmonary blood flow and an increased pulmonary venous return to the left atrium. The left atrial pressure rises, encouraging the flow of oxygenated blood across the interatrial communication into the right heart and the systemic circulation.

Clinical evaluation of treatment with prostaglandin. An extensive assessment of the use of infusion of $\mathrm{PGE}_{1}$ in treating infants with ductus dependent congenital heart disease was undertaken in a collaborative clinical trial in the United States involving 492 infants. ${ }^{9}{ }^{10}$ In almost all the cases in the study the infusion was continued for no more than several hours, the objective being to stabilise the infant in preparation for emergency palliative surgery. $\mathrm{PGE}_{1}$ (rather than $\mathrm{PGE}_{2}$ ) was chosen for the trial for theoretical reasons, although $\mathrm{PGE}_{2}$ had seemed equally effective. The earlier reports and the collaborative study emphasised the use of infusion of $\mathrm{PGE}_{1}$ or $\mathrm{PGE}_{2}$ for a period of a few hours before emergency surgery. Longer term infusion was initially reported in preterm infants, but enthusiasm for its use has probably been limited partly by practical considerations as well as by an appreciable incidence of side effects. ${ }^{6} 10$ The use of an oral preparation of $\mathrm{PGE}_{2}$ has simplified long term administration. ${ }^{11} 12$

In infants with a ductus dependent pulmonary circulation a single oral dose of $\mathrm{PGE}_{2}$ caused an increase in arterial oxygen content similar to that reported in the US collaborative study when intravenous infusion of $\mathrm{PGE}_{1}$ was used. Arterial oxygen saturation and plasma $\mathrm{PGE}_{2}$ concentration reached similar values whether $\mathrm{PGE}_{2}$ was given orally or by intravenous infusion. These values increased within 15-30 minutes after an oral dose, implying rapid absorption from the alimentary tract. A larger dose caused a proportionately greater increase in plasma $\mathrm{PGE}_{2}$ concentration, confirming that absorption was efficient. Higher plasma $\mathrm{PGE}_{2}$ concentrations, however, were not usually associated with better blood oxygenation, probably because the ductus had been fully dilated by the lower dose. These observations have helped to rationalise both the route of administration and the appropriate dosage.

Hourly administration of oral $\mathrm{PGE}_{2}$ is necessary to maintain arterial oxygenation at satisfactory 
levels for the first week or two. Subsequently, the dosage or its frequency can be reduced. The ductus arteriosus did not remain patent if treatment with $\mathrm{PGE}_{2}$ was stopped, even after many months of treatment, but in some infants it has been possible to lengthen the periods between doses to as much as every 4-6 hours to treat them at home. Long term treatment encouraged growth of the infants and of their pulmonary arteries, which seemed to be advantageous to the surgeons when they performed palliative shunts.

Complications of $\mathbf{E}$ type prostaglandins. The incidence of complications in the first 62 patients treated in Birmingham with $\mathrm{PGE}_{2}$ (oral or intravenous, or both) ${ }^{12}$ was compared with those reported in the US collaborative study in which intravenous $\mathrm{PGE}_{1}$ was used. ${ }^{10}$ Apnoea and cardiovascular complications were much less common during low dose treatment with $\mathrm{PGE}_{2}$ than during infusion of $\mathrm{PGE}_{1}$, but diarrhoea and mild fever were more common. Necrotising enterocolitis was a rare complication in both studies, usually related to cardiac catheterisation. Complications such as cortical hyperostosis, friability of the ductus arteriosus, or damage to pulmonary vascular smooth muscle have been described after long term treatment with $\mathrm{PGE}_{1}$. None were seen in infants treated with long term $\mathrm{PGE}_{2}$, probably having been avoided by the low dosage used in Birmingham.

Rationale of treatment with prostaglandin $\mathbf{E}$. There are distinct advantages in using the oral preparation in preference to the intravenous one. It is easier to administer and its absorption and beneficial effects are rapid. It is particularly suitable for long term use and it has enabled most infants so treated to grow satisfactorily. There may also be an economic argument in favour of $\mathrm{PGE}_{2}$ : the cost of the intravenous preparation is one fifth the cost of $\mathrm{PGE}_{1}$ and the daily cost of treatment with the oral preparation is only $14 \%$ the cost of an ampoule of PGE $_{1}$.

Treatment with oral $\mathrm{PGE}_{2}$ is usually begun as soon as the diagnosis has been established by cross-sectional echocardiography. If a subsequent diagnostic cardiac catheterisation is to be performed it is better done when the neonate's oxygenation and metabolic state have been improved. Treatment may be begun in the neonatal unit before transferring the infant to the cardiac referral centre, preferably after consultation with the cardiologist because there are potential risks if infants with total anomalous pulmonary venous return or persistent fetal circulation are inadvertently given prostaglandin E.
The initial oral dosage of $\mathrm{PGE}_{2}$ should be 20-25 $\mu \mathrm{g} / \mathrm{kg}$ hourly, decreasing the dose frequency after the first week. When gastrointestinal absorption is expected to be poor, when oral treatment is ineffective, or if diarrhoea becomes troublesome an intravenous infusion should be begun in a dose of $0.003 \mu \mathrm{g} / \mathrm{kg} / \mathrm{min}$. Occasionally it is necessary to increase the infusion dose for a few hours and it is exceptional to have to use doses as high as 0.01 $\mu \mathrm{g} / \mathrm{kg} / \mathrm{min}$. There seems to be little justification for the continued advocacy of doses as high as $0 \cdot 05-0 \cdot 10$ $\mu \mathrm{g} / \mathrm{kg} / \mathrm{min}$ even if $\mathrm{PGE}_{1}$ is used. Infants may be treated with oral $\mathrm{PGE}_{2}$ for between one and four weeks initially, and then decisions should be made on an individual basis whether to proceed with surgery or to plan a longer course of treatment to encourage further growth.

\section{References}

1 Coceani F, Olley PM, Bodach E. Lamb ductus arteriosus: effect of prostaglandin synthesis inhibitors on the muscle tone and the response to prostaglandin $\mathrm{E}_{2}$. Prostaglandins 1975;9:299-308.

2 Gersony WM, Peckham GJ, Ellison RC, Miettinen OS, Nadas AS. Effects of indomethacin in premature infants with patent ductus arteriosus: results of a national collaborative study. J Pediatr 1983;102:895-906.

${ }^{3}$ Peckham GJ, Miettinen OS, Ellison RC, et al. Clinical course to 1 year of age in premature infants with patent ductus arteriosus: results of a multicenter randomized trial of indomethacin. J Pediatr 1984;105:285-91.

${ }^{4}$ Rennie JM, Doyle J, Cooke RWI. Early administration of indomethacin to preterm infants. Arch Dis Child 1986;61:233-8.

5 Elliott RB, Starling MB, Neutze JM. Medical manipulation of the ductus arteriosus. Lancet $1975 ; \mathrm{i}: 140-2$.

6 Olley PM, Coceani F, Bodach E. E-type prostaglandins. A new emergency therapy for certain cyanotic congenital heart malformations. Circulation 1976;53:728-31.

7 Neutze JM, Starling MB, Elliott RB, Barratt-Boyes BG. Palliation of cyanotic congenital heart disease in infancy with E-type prostaglandins. Circulation 1977;55:238-41.

${ }^{8}$ Heymann MA, Berman W Jr, Rudolph AM, Whitman V. Dilatation of the ductus arteriosus by prostaglandin $E_{1}$ in aortic arch abnormalities. Circulation 1979;59:169-73.

9 Freed MD, Heymann MA, Lewis AB, Roehl SL, Kensey RC. Prostaglandin $E_{1}$ in infants with ductus arteriosus-dependent congenital heart disease. Circulation 1981;64:899-905.

10 Lewis AB, Freed MD, Heymann MA, Roehl SL, Kensey RC. Side effects of therapy with prostaglandin $E_{1}$ in infants with critical congenital heart disease. Circulation 1981;64:893-8.

1 Silove ED, Coe JY, Shiu MF, et al. Oral prostaglandin $E_{2}$ in ductus-dependent pulmonary circulation. Circulation 1981;63: 682-8.

12 Silove ED, Roberts DGV, De Giovanni JV. Evaluation of oral and low dose intravenous prostaglandin $E_{2}$ in management of ductus dependent congenital heart disease. Arch Dis Child 1985;60:1025-30. 